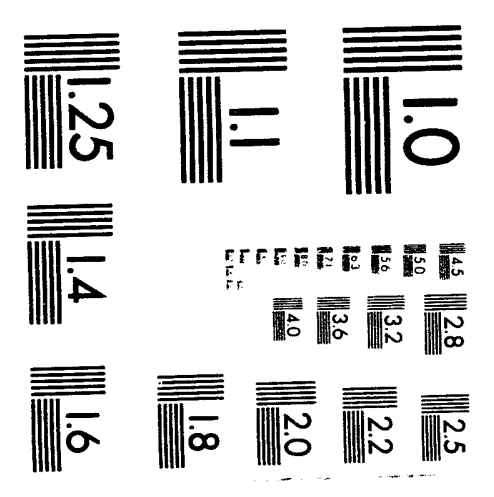



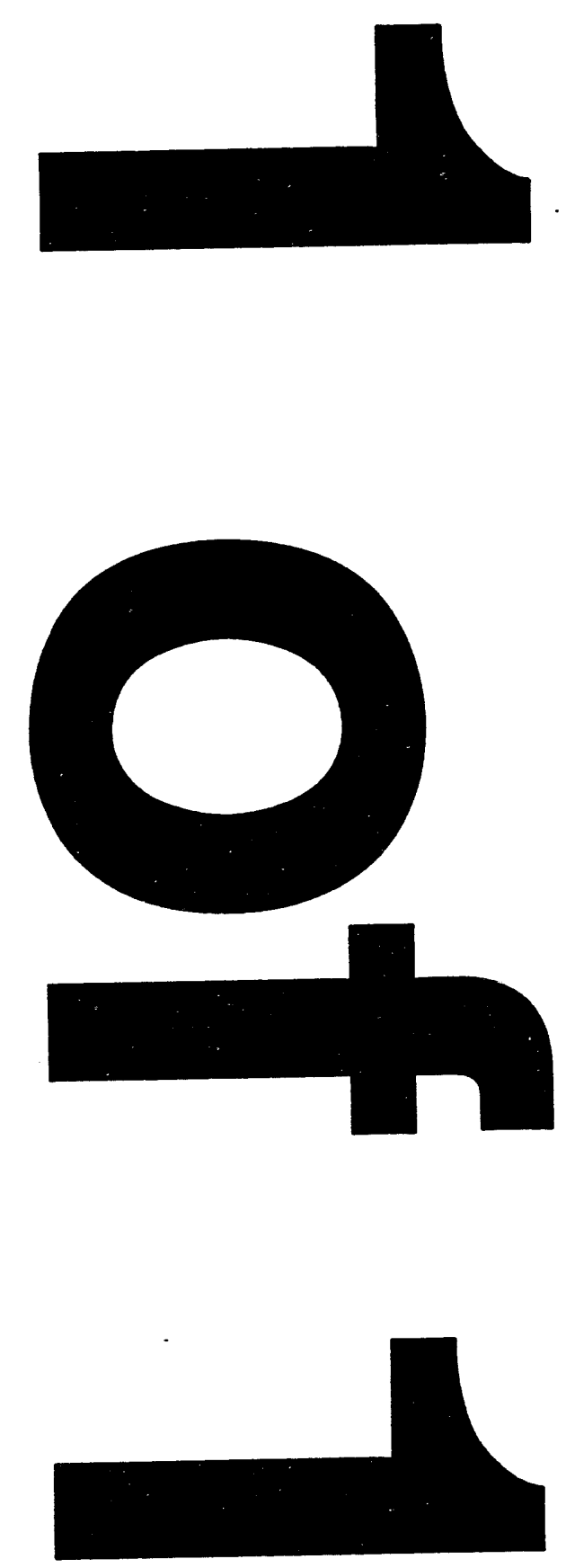


$$
1 A A-54 B=-94-25
$$

30 June 1993
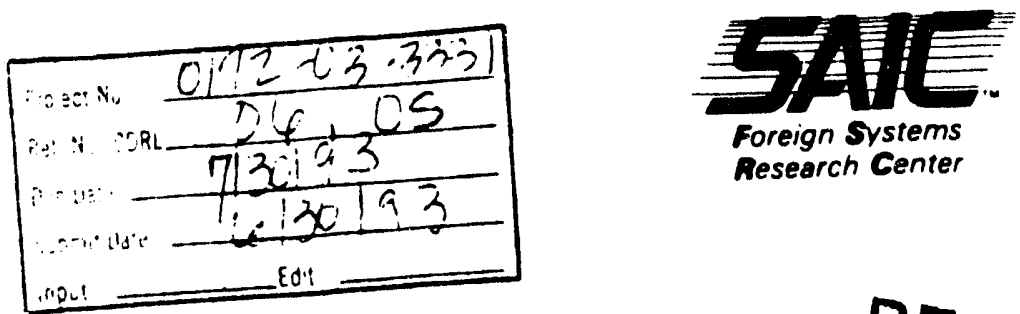

Notra Trulock

Los Alamos National Labs

MS \# A112

Los Alamos, NM 87545

Subject: Final Report on N-STAR/MAGE Project, Contract No. 9-XQ2-1590D-1

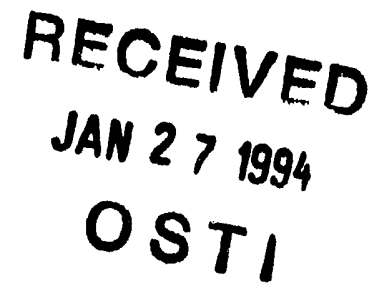

Dear Mr. Trulock:

This is the final report on the N*IMAGE project and is a deliverable item (CDRL 06) under the terms of the contract. It contains a brief abstract of the project background, objectives, efforts taken to achieve the objectives and publications provided.

\section{Background and Objectives}

The Soviet Union has devolved into various autonomous republics, each having individual nationalistic agendas, yet retaining many of the indigenous capabilities and facilities that were present prior to the dissolution of the USSR. Military forces, especially nuclear, still exist in spite of the changes in the overarching control hierarchy. The Commonwealth of Independent States [CIS] has been created, ostensibly maintaining control over the strategic forces of the now-defunct Soviet Union. These changes have created an identifiable need to understand the old forces in a new context. Additionally, as the military dimension of the U.S./Russian/CIS relationship fades, it is important to understand the political, social, and economic structures that bear on the new environment. Information on the individual republics and former Soviet Union is coming in at a staggering rate; it must be assimilated and analyzed while being careful not to lose those existing data points and analysis of Soviet information that are still relevant to new assessments of the republics and the CIS.

The objective of the proposed FSRC work was to provide user-friendly, automated analytical tools to assist the analyst in assessing various aspects of Russia and CIS Nuclear Weapons. For each, the data package includes an extensive, free-form, interactive database system (N-STAR), a hierarchical structure of questions which lead an analyst through the essential elements of the related decisionmaking process (IMAGE), and an instruction manual explaining the use of the systems and their interrelationships. Relevant data supporting the analysis will be available in a standard format on the same system, facilitating data fusion and assessment. These analyst tools are in the form of Macintosh-compatible software systems (N-STAR and IMAGE) along with supporting documentation.

The schedule was to deliver the N*IMAGE module "CIS Nuclear Weapons" five months after the contract initiation and the second module, "Russia," nine months after contract initiation. The FSRC was to provide on-site installation and training support to CNSS analysts. For each data module, the FSRC also would provide an instruction manual detailing the use of the system and interactions. 
Notra Trulock

30 June 1993

Page 2

\section{Process and Results}

The contract was initiated on 01 October 1992 and FSRC work commenced immediately. It was accomplished through a series of subtasks, duplicated for each of the two separate data modules. The basic project sequence consisted of (1) tailoring the existing N-STARMMAGE software to "Russia" and "CIS Nuclear Weapons" requirements; (2) establishing and adding the windows for specific subcategories of information desired by the sponsor, (3) performing data collection, evaluation, and entry into the databases (N-STAR); (4) writing the appropriate hierarchy of questions (IMAGE) that focus on the relevant decisionmaking process; (5) writing the supporting documentation and user's manual for the specified N-STAR/MAGE package; (6) installing the completed N-STAR/MMAGE system on a CNSS computer and providing on-site training during the delivery visit.

1) Software Structure. This task established the N-STAR/IMAGE software for new data entry. For each of the two new modules, an existing blank N*IMAGE software shell was assigned. New maps were drawn and the master copy was created. A blank IMAGE software shell was prepared also.

2) New Data Windows. After consultation with the CNSS sponsor, new data windows were added to the existing software shells. The existing shells contained data categories titled Economic, Political, Social Organizations, International Relations, Infrastructure, Demographics, Military Forces, Maps, TO\&E, Commands, Weapons, Technical Characteristics, Decision Reference, Planning, Military Art, Military Organizations, Terminology, Biography, Current Events, and Bibliography. For the CIS Nuclear Weapons package, the following new data windows were added: Research and Development, Nuclear Policy, Nuclear Weapons Control, Personnel, Nuclear Weapons Security, Space Applications, Arms Control, Nuclear Weapons Targeting, Strategic Warning, and Environmental Issues. For N*IMAGE on Russia, these same categories were retained and three new ones were added: Religion, Disintegration, and START Facilities.

3) Data Population. The next effort was devoted to populating the new software data shells with appropriate information and had three distinct elements for each piece of data.

- Data Collection. FSRC researchers investigated thousands of open sources related to Russia and the other former Soviet republics. Initial data gathering had to generate the database entries, as well as provide a better understanding of the general relationships between data for the subjects under study. General categories for data collection were those described in paragraph 2, above. The existing FSRC library routinely receives Russian and republic source material, secondary sources discussing Russia and the other republics, and general technical reference material. The library was the basis for the collection effort. Since the focus of this effort is to understand the perceptions of another entity, data collectors, wherever possible, used 
Notra Trulock

30 June 1993

Page 3

indigenous publications which authoritatively discussed relevant issues. Part of the collection process included data files made available to the FSRC by CNSS; appropriate data was made available on disk by CNSS and incorporated into the $\mathrm{N}^{*}$ data collection. Additionally, FSRC researchers checked appropriate publications from local libraries and on-line sources, including those available on Internet.

- Data Evaluation. Prior to data entry into the N-STAR system, individual pieces of data were assessed with regard to validity, context, applicability, and data system location. This was completed by Mr. Beachley, the research task leader. Also, the appropriate linkages to other data elements needed to be specified to ensure that the analyst, when accessing that data, is automatically directed to other relevant information.

- Data Entry. Each evaluated and interpreted piece of data was individually entered in an existing card format. This involved selection of appropriate data elements from sources, properly paraphrasing when necessary, linking the data to other pieces of data, and making appropriate records of the entry. The data was entered by "windows" (categories) into the N-STAR system for either CIS Nuclear Weapons or Russia. Even if no information for a particular window was found in the sources available to the FSRC, the window was left open and accessible to facilitate later addition of information as it becomes available.

4) IMAGE Questions. Emulative techniques developed by the FSRC were used to develop new questions pertaining to Russia and CIS nuclear weapons in the IMAGE system. This subtask relied heavily on existing FSRC knowledge of topic, as well as knowledge acquired during the data collection, evaluation, and entry subtasks. The decisionmaking process is represented as a series of questions about an objective condition. It has four basic steps: describe the scenario (conditions), describe perceptions of the scenario, forecast potential actions in response to perceptions, and summarize. In the first step, the analyst must develop the particular context or scenario against which the decision process will be applied. The IMAGE questions will lead him to a comprehensive outline of the envisioned situation. The context must include some change or action which serves as the catalyst for initiating the decisionmaking process which is to be emulated. The next major block of questions in the IMAGE logic path covers "What would the subjects perceive?" and helps to reconstruct the subject's perceptions of the underlying characteristics of the situation or premise. This is followed by another major group of questions called "What might the subject do?" Potential decisions about military, economic, political, and social/cultural issues are included. Finally, the system summarizes the responses so the analyst can evaluate the entire scenario and potential outcomes. 
Notra Trulock

30 June 1993

Page 4

For the IMAGE system on CIS Nuclear Weapons, a separate decisionmaking emulation sequence was developed for each of the four nuclear weapon-holding republics: Russia, Ukraine, Belarus, and Kazakhstan. In the case of Russian nuclear weapons, it was further subdivided to represent the views of Yeltsin (and his supporters) or the conservative, hard-line faction. For the $N^{*}$ MMAGE/Russia module, the IMAGE process represents three separate decisionmakers: Yeltsin and his supporters; hard-line nationalists; and regional leaders.

5) Operating Manuals. Technical summary documentation of the N-STAR and IMAGE system was provided in the form of individual instruction manuals. The User Manuals allow the analyst to understand the relation between N-STAR and IMAGE for that software package and guide the analyst through the use of the system to emulate decisionmaking for that particular entity. A 140-page manual was created and provided with each N*IMAGE module. They each contain an executive summary, system description, operating procedures and tips, a tutorial, and a glossary. Manuals were provided at the time of software delivery for each module.

6) Installation and Training. When the first data module was completed, the FSRC delivered it to CNSS and installed it on a compatible computer system. The N*IMAGE/CIS Nuclear Weapons Package (and User Manual) was delivered and installed on 02 March 1993. The appropriate floppy disks were left with the COTR as a backup. During the delivery/installation visits, FSRC representatives (Chris Ragaisis and Dave Beachley) provided training to CNSS personnel as designated by CNSS. The training consisted of a system demonstration, question and answer, and hands-on operating opportunity. In accordance with Mr. Zamora's letter of 16 June 1993, the package for Russia will be delivered and installed on your computer during your personal visit to our Denver office. Based on your stated travel plans, we anticipate that occurring 01 July 1993. The appropriate floppy disks and User Manual also will be provided at that time.

\section{Publications}

The final results of the project included:

- $\quad$ one set of data and applications disks containing the N*IMAGE system for "CIS Nuclear Weapons";

- a User's Manual for N*MMAGE/CIS Nuclear Weapons;

- one set of data and applications disks containing the $N^{*}$ IMAGE system for "Russia";

- a User's Manual for N*IMAGE/Russia. 
Notra Trulock

30 June 1993

Page 5

It has been a pleasure working with you and I look forward to the opportunity to support you again in the future.

Sincerely,<smiles>C#CCCCC</smiles>

Robert K. Driver

cc: Jane Ohrbom (SAIC Corporate Contracts)

M. Zamora (LANL Senior Contract Administrator)

\section{DISCLAIMER}

This report was prepared as an account of work sponsored by an agency of the United States This report was prepared as an account of wornment nor any agency thereof, nor any of their Government. Neither the United States Government nor assumes any legal liability or responsiemployees, makes any warranty, express or implied, or assumes any legal apparatus, product, or bility for the accuracy, completeness, or usefulness of any infor privately owned rights. Referprocess disclosed, or represents that its use would not infringe privately owned rights. Remark, ence herein to any specific commercial product, process, or servitu its endorsement, recommanufacturer, or otherwise does not necessarily constitute or imply its endorsement, recommendation, or favoring by the United States Government or any state or reflect those of the and opinions of authors expressed herein do not 

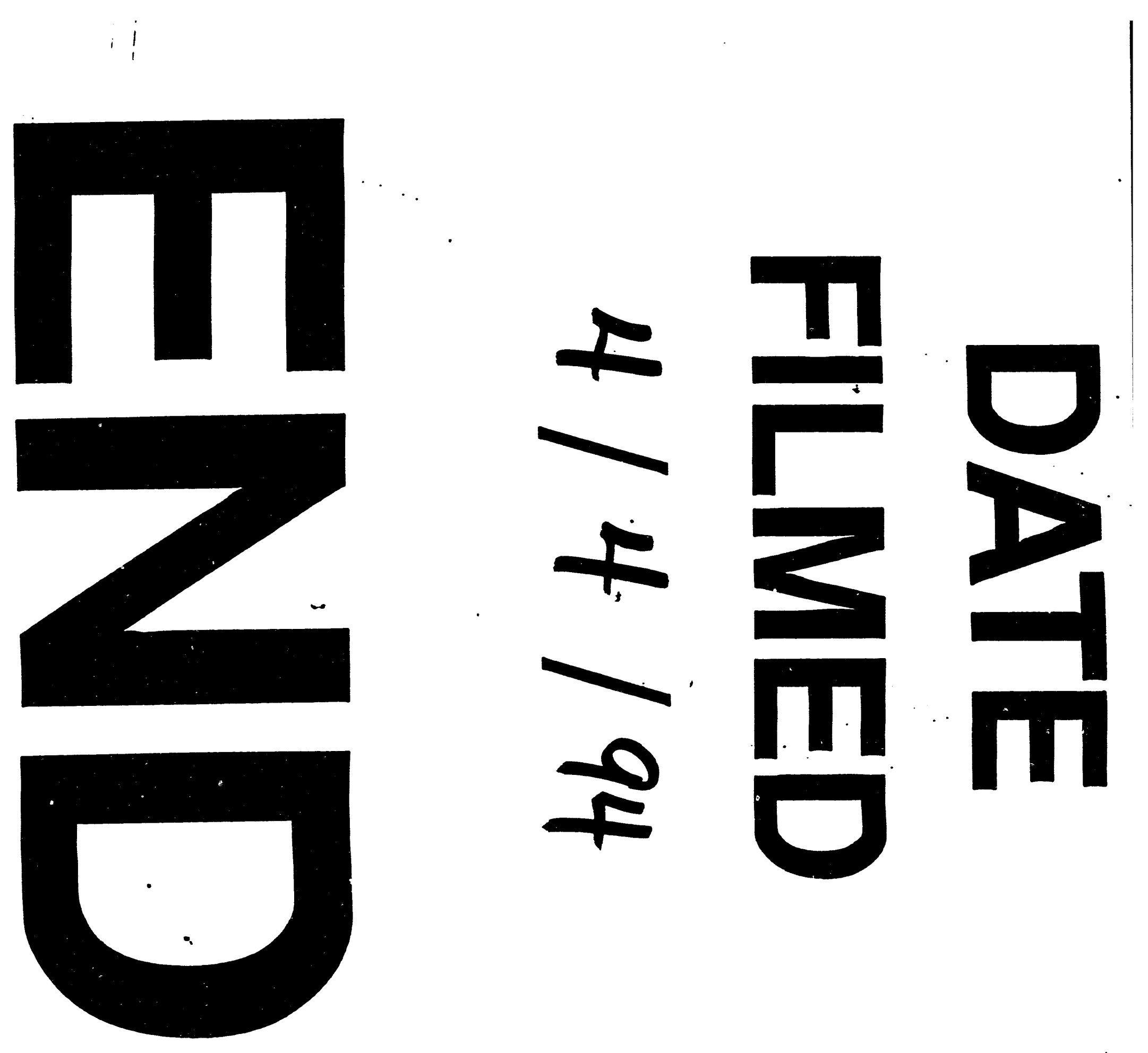
